\title{
The Observation, Inquiry, and Measurement Challenges \\ Surfaced by Complexity Theory
}

\author{
by Eric B. Dent
}

Chapter in Managing the Complex: Philosophy, Theory and Practice edited by Kurt Richardson.

One of the contributions of the work in complexity theory is its demonstration that traditional science has not done an adequate job of establishing effective processes for observation, inquiry, and measurement. The domain of interesting organizational phenomena that can be adequately addressed by arms-length, objective measurement has been relatively exhausted. An exploration of most topics of appeal, such as strategy, innovation, leadership, communication, and so forth has been stunted by an inadequate depiction of how they operate.

A more comprehensive approach to observation, inquiry, and measurement is perspectival observation, a term adapted from Schwartz and Ogilvy (1979), which connotes not anything-goes-subjectivity, but the differences in perspective which arise when observing from a different "place" - "place" meaning everything from geographical position to psychologically-embedded history. Consequently, two different people viewing the videotape of the beating of Rodney King by the Los Angeles police can reasonably see different things - depending on their views of race relations, past experiences with police, knowledge of what it takes to subdue a belligerent person, and 
so forth. They could not, however, reasonably see a reenactment of the musical "Chicago" in the tape. This distinction is succinctly captured by Stewart and Cohen (1997):

The message is not that reality doesn't exist, nor that it can be anything you want it to be. The message is that reality is not the same as your observation of it: that is just one shadow out of many. Reality is whatever casts all those interrelated shadows, and you can infer some aspects of its structure by looking at how different shadows are interrelated. (200)

Perspectival observation also connotes that the measuring process may alter the phenomenon being measured (Dent, 1999). This dilemma can be illustrated with a thermometer and a bucket of water. If the water is "cold" and the thermometer is at room temperature, when the thermometer is inserted into the water it will raise the temperature of the water, slightly. There is no way to get around this effect. The thermometer would need to be at precisely the same temperature as the water not to change the temperature. However, a circularity arises since the only way to know the temperature is to measure it. For most everyday purposes, though, the change in temperature caused by the measurement process is insignificant and irrelevant to the purpose of the measurement. In the organizational and other social sciences, however, this effect is often not negligible.

The purpose of this chapter is twofold. 
(1) to gather in one place, the measurement and inquiry challenges surfaced by complexity theory. Most of these have been addressed, separately, elsewhere.

(2) to offer insights into how complexity theory can better inform both organizational researchers and practitioners as they deal with these measurement challenges.

In addition to typical organizational examples, I will use illustrations from newspaper stories, movies, and other pedestrian sources to demonstrate the real-world pervasiveness of the difficulty of observation and measurement in contemporary social science issues.

\section{Observation, Inquiry, and Measurement Challenges}

The following proposed taxonomy is one way of framing a discussion of the observation and measurement challenges. The seven headings are merely illustrative. There is no suggestion that these categories are the most significant of all possible categories or even all inclusive. Although I have endeavored to make them as distinct from each other as possible, there is some overlap. Seven categories of problems inherent in observing and measuring complex phenomena are.

- $\quad$ Even the Most Straightforward Rules or Definitions Require Interpretation

- How and What to Measure

- Unintended Projection of Those Conducting the Measurement

- The Phenomenon of Interest is Never Directly Measured (the Issue of Proxy)

- $\quad$ Recalibrated Understanding of Measurement Instruments (Beta Change) 
- $\quad$ Awareness of Being Measured (Knowing Subjects)

- The Act of Measurement Inevitably Changes the Phenomenon Being Measured

\section{Even the Most Straightforward Rules or Definitions Require Interpretation}

Put aside, for the moment, the measurement of leadership, spirituality, or attitudes. What could be more straightforward than the measurement of height? As it turns out, there is controversy in determining which building is the tallest in the world. The determination of height is so sticky that in 1969 the Council on Tall Buildings was established to make judgments about height. The two leading contenders are the Petronas Towers in Kuala Lumpur, Malaysia and the Sears Tower in Chicago, USA. The Sears Tower has 110 stories while the Petronas Towers has 88. The highest occupied floor of the Sears Tower is some 200 feet above that of Petronas. However, Petronas has a "spire" which raises its crown to 1,483 feet. The roof of the Sears Tower is at 1,450. The Sears Tower has antennas which extend to 1,703 feet. By decree of the Council, though, spires count and antennas don't (Haggerty, 1996). The problem is not so neatly solved at this point. There can be at least several steps of regress as the definitions of "spire" and "antenna" are interpreted, their subelements defined and interpreted, and so on.

A similar story is charmingly told in the movie "The Englishman Who Went Up a Hill but Came Down a Mountain" starring Hugh Grant. The film tells the story of British cartographer Reginald Anson who in 1917 was charged with surveying the height of 
Ffynnon Garw, the esteemed "mountain" in Wales. Unfortunately, for the proud Welsh of the area, Ffynnon Garw measures 984 feet, 16 feet short of a "mountain" designation and would have to be re-classified as a hill. Horrified by the thought that their "mountain" will be lost, the locals decide to increase the height of Ffynnon Garw by twenty feet (which they do be delaying Anson's departure while they add dirt to the top). So, not only is height a factor, but so is the timing of the measurement since the height of mountains can apparently change (See Awareness of Being Measured (Knowing Subjects) below).

\section{How and What to Measure}

Before the 1998 season the American major college football teams launched a ranking system known as the Bowl Championship Series (BCS). The BCS was installed to ensure that the best two teams each year would ultimately play each other in a bowl game, resulting in a clear "best" team of the year. It was also supposed to minimize the subjectivity of coaches' or sportswriters' opinions in the rankings. The BCS uses a computer average of information compiled by eight "experts." Each expert has a different formula which may include factors such as schedule strength, margin of victory, early-season-results vs. late-season-results, opponents' opponents' winning percentage, among others. Ironically, the BCS has generated as much, if not more, controversy than it was intended to resolve. About every two or three seasons, fans have generally agreed that the BCS "didn't get it right." 
Perhaps, having more commercial implications than the Bowl games are the "hits" to web sites. Advertisers are paying for "eyeballs captured," so measuring web "traffic" is an important activity. The three major internet rating firms are Media Metrix, Nielsen/NetRatings, and PC Data. During one three month period, PC Data reported a 21 percent increase in people visiting About.com. Media Metrix showed traffic remaining the same and Nielsen/NetRatings claimed a 12 percent drop (Cha, 2001). A variety of explanations account for some of the differences. For example, some rating firms don't count users who are younger than eighteen, others count PC users and not Mac users, and still others treat web hits from a work location differently from those made on a home computer. Although some of these differences will be sorted out in time, the "interpretation" issue muddies the water. As I write, I am "working," but I am at home and it is Saturday. Should a rating firm categorize my web activity in support of this chapter as "work" or not?

Most people probably do not realize that there are competing philosophies about how statistics on crime, unemployment, headcount, and many other important public policy characteristics are measured. In May 2001, the Federal Bureau of Investigations (FBI) released its 2000 crime figures which showed no change from 1999. The media generated headlines about the end of the seven-year decline in crime and the need for greater law enforcement strategies. A month later, the Justice Department released its figures showing that crime in general had decreased 10 percent from 1999 to 2000 (Murray, 2001). Why the difference? The FBI tabulates crimes reported to law 
enforcement agencies. The Justice Department surveys a representative sample of homes and asks them crime-related questions (not including whether the crime was reported). Likewise, some government agencies count the actual employment in the United States while others survey households about the employment, or lack thereof, by those in the household.

Perhaps the greatest source of statistical controversy in the United States is the decennial census. The results of this census determine congressional representation, the flow of federal dollars into social programs, and other important allocation of

resources. Federal law requires that each person be counted. Some people assert that the census results in an undercount because it may miss those who are homeless, those who are illegal immigrants, etc. (even though these groups are pursued by census takers). Interestingly, those who assert an undercount can offer what they describe as a fairly precise measure of the undercount (often based on representative sampling).

\section{Unintended Projection of Those Conducting the Measurement}

This measurement threat is, perhaps, best encapsulated in Figure 1, "I wouldn't have seen it if I had not believed it." If you read the last line quickly, you may not have noticed that this is a reversal of the maxim, "I wouldn't have believed it if I had not seen it." Figure 1 points out that what people actually "see" is to some degree determined by their belief systems. The movie "Contact" based on Carl Sagan's best-selling 1985 
novel nicely illustrates the tension between prior belief and observation. Jodie Foster plays Ellie Arroway, once a researcher for the SETI (Search for Extraterrestrial Intelligence) Institute and then a free-lance extraterrestrial intelligence searcher, who has an experience that contradicts her scientific beliefs. The final storyline of the movie is Foster's attempt to rationalize or reconcile her scientific training with her actual experience.

[Figure 1 here] You can view it at: http://www.uncp.edu/home/dente/seebelieve.gif

A "real" version of "Contact" occurred after moon samples were brought back by the Apollo astronauts. Prior to the initial moon landing, scientists had spent decades developing a comprehensive body of theoretical work. Mitroff (1974) interviewed 42 leading scientists of the Apollo space program at four intervals before and during the collection of moon samples. These samples would provide strong evidence in favor of and in opposition to a number of the theories at the time concerning topics such as age of the moon, general geochemical and petrological results, and seismic and magnetic results. In general, in spite of the evidence accumulating to strengthen the evidence for the work of certain scientists, those who became out of favor continued to hold their prior beliefs. "In the words of a number of the respondents: 'They [referring to the other scientists] just don't change, do they? But then, perhaps if I were honest with myself I'd say I haven't changed much either and again I'm not so sure that it is always bad for science for scientists not to change easily, although it can be extremely dangerous and 
irritating at times"' (Mitroff, 1974, 167). Consistent with the notion of perspectival observation, Mitroff makes the case that it is important for scientists to have strong emotions and commitment to ideas in order to be most effective. James Falconer's chapter, "Unresolved Issues in Process-Centric Business Analysis: A Cathartic Role for Complexity," provides greater detail about how academics, researchers, and practitioners all easily embrace models even though aspects of the modeled phenomenon depart from the model's predictions.

Max Planck (1949) is famous for writing, "a new scientific truth does not triumph by convincing its opponents and making them see the light, but rather because its opponents eventually die, and a new generation grows up that is familiar with it" (33-34). His assertion is that it is unlikely that unintended projections can be removed by training or evidence. The new "truth" is accepted when the preponderance of old adherents die.

\section{The Phenomenon of Interest is Never Directly Measured (the Issue of Proxy)} As pointed out in How and What to Measure, in the social sciences, we never directly measure the phenomenon of interest. We measure a proxy. The critical issue in every measurement, therefore is, how well the proxy represents the phenomenon of interest. In the past, some proxies provided fairly good estimates. Now, these have broken down. For example, former United States Senator Daniel Patrick Moynihan focused at the end of his career on inaccuracies in the consumer price index $(\mathrm{CPI})$. This index is incredibly important to economic activity. A commission of scholars in the mid 1990s 
concluded that if the "CPI overstates inflation by one percentage point per year through 2005 , this will add almost $\$ 140$ billion to the deficit that year and $\$ 634$ billion to the national debt" (Will, 1996). The CPI is an attempt to measure the "cost of living." In fact, it measures a fixed "market basket" of goods updated infrequently. Although there have been improvements since Moynihan's work, the CPI still does not accurately reflect how people live, the value of products with changing features (when CD players become standard in cars, for example), and substitutions (if beef prices skyrocket people buy less).

The proxy issue is important in assessing the effectiveness of teachers. How are great teachers identified? The 1985 and 1986 Florida Teacher of the Year recipients were both denied merit increases under the merit pay program in place at the time. The awards were given because of the teachers' enthusiasm, dedication, involvement with students, and innovation in the classroom. The merit pay formula heavily emphasized factors such as how promptly a teacher begins and ends class, whether the lesson plans are properly designed, whether there are quantifiable learning objectives for each class and so forth. The merit pay program apparently makes the common error of measuring what is easy to measure, which is often a poor proxy for the phenomenon of interest.

Nielsen Media Research is the world's leading company in measuring television viewers. The Nielsen ratings are extremely important, essentially dictating which shows continue to be aired and determining the price of commercial advertisements. Nielsen 
measures TV viewership in a variety of ways including electronic meters (People Meters) on the sets of 5,000 representative homes requiring viewers to press an "I'm watching" button, instruments that record to which station the set is tuned in other homes, and diaries kept by viewers of the shows they watched in still other homes. Measuring TV viewing, as with most other social phenomena of interest, has become increasingly more complex and controversial. Years ago, when only diaries were used, the system was very reliable because TV viewing consisted of discrete events. Viewers turned on their sets at an appointed time to view a particular show(s) drawn from a limited set of choices. Journalers were also much more diligent about accurately recording their viewing. Today, even with electronic People Meters, there are several issues that confound accurate measurement. In many homes, the TV(s) is on for extended periods of time even though it is not actually being watched. People are less diligent about record keeping and pressing the "I'm watching" button. Finally, the development of remote control has created the sport of channel surfing, viewers are using a variety of devices to record a show and (possibly) watch it later, and inventors have created various products so that commercials may be muted or not viewed at all.

\section{Recalibrated Understanding of Measurement Instruments (Beta Change)}

Beta change is a term that reflects a change in the measurement instrument during an inquiry process (Golembiewski \& Munzenrider, 1976). In other words, the "yardstick" for the measurement is not the same when used to take measurements at two different times. Imagine a three-day training course on managing diversity. On Monday 
morning, the participants, predominately white males, are given a pre-test with questions such as, "in your business dealings, how frequently do you discriminate against women and people of color?" The most frequent responses are "never" and "rarely." Then the participants go through a three-day experience in which their awareness is raised so that they can see their behaviors in ways that they previously could not. When responding to the same question Wednesday evening, the most frequent responses are "rarely" and "occasionally." The conclusion drawn from a classic experimental design would be that the training increased prejudice in the participants. Anyone familiar with these training courses knows that is not what happened. In fact, the shift in awareness meant the yardstick did not measure on Monday what it measured on Wednesday.

Beta change is apparently also a factor in the reporting of crime statistics as discussed in How and What to Measure. In addition to the difference in the data collected by the Justice Department and the $\mathrm{FBI}$, there has been a difference in the percentage of crime reported over time. Hispanic women, for example, reported only 47 percent of the violent crimes against them in 1999, but reported 61 percent in 2000 (Murray, 2001). In the span of one year, reporting rates increased in virtually every demographic category. The beta change that took place was a change in the extent to which people viewed victimization as inherent in their way of life. When people do not believe that the police are effective against crime, they do not report crimes, treating them instead as "personal problems." However, when crime rates drop, people believe that the police can do 
something about what is happening to them. Consequently, they report more crimes. The possibility of beta change exists in nearly all social studies and must be addressed by serious researchers.

\section{Awareness of Being Measured (Knowing Subjects)}

For several years, Business Week (BW) magazine biannually has been conducting research in order to rank the top business schools in the country. BW takes the "customer's" point of view and asks students and the companies that hire them to rate their experiences with the business schools. In its 1998 ranking of MBA programs, BW complained that the students had not participated fairly because students at some schools had circulated memos saying "If you have complaints about your program, the BW survey is not the place to air them." Rather than create a research design that accounted for knowing subjects, who have an incentive for their schools to rank highly, BW described the students' behavior as "cheating."

In the How and What to Measure section I discussed measuring web site "hits." Another factor in that measurement is the wide range of screen "refresh" times employed by web page providers. A frequent refresh rate is necessary for changing data such as sports scores or stock prices. Static web pages, however, do not need refreshing. Each refresh is counted as an additional web site hit. Sites such as AltaVista and Lycos have been accused of inflating their web hits by using a refresh rate 
of only five minutes (Cha, 2001). NetRatings has assigned staff solely to the problem of web site hit manipulation.

A special case of "knowing subjects" is induced measurement. An effort is made to predict a measurement based on very precise and careful current measurements. However, all things do not remain the same so that the predicted measurement is impacted by the unanticipated actions of agents. Perhaps, the most well-known induced measure is that of traffic. Urban planners can measure fairly accurately the amount of traffic in a given area. They then determine how much traffic a new road could accommodate. However, that factor has to be adjusted because additional traffic is generated by the new road. People who took the subway because it was incrementally better for them now find that driving is better. People who limited trips because of waiting in traffic now take the additional trips. To account for induced traffic, planners often include a 30 percent increase factor.

Making a simple 30 percent adjustment is not always successful, as hydrologists in charge of measuring flood levels of the Red River learned in the spring of 1997. Computer models account for some sandbagging on the part of people threatened by flood. What the modelers didn't realize, though, is that the higher the water level rises, the more people fear damage and loss to their property. Consequently, they will participate in even more sandbagging, which causes the water level to rise higher still. As the modelers began to understand the unprecedented volume of sandbagging that was taking place, they adjusted their initial expected crest level from 49 feet on April 
$13^{\text {th }}$ to 50 feet on April $14^{\text {th }}$. However, news that the water height was expected to be even higher caused people to sandbag even more. On April $16^{\text {th }}$ the prediction was changed to 50.5 feet. On April $17^{\text {th }}, 52$ feet. On April $18^{\text {th }}$, the final prediction was 53 feet ("Sandbagging," 1997). The crest was actually 54.11 feet. The volume of water was accurately projected on April $13^{\text {th }}$. The ongoing sandbagging and height of the water was never accurately projected. The induced effect was always underestimated.

\section{The Act of Measurement Inevitably Changes the Phenomenon Being Measured}

I have never had my blood pressure measured accurately. To be more precise, my blood pressure in the presence of medical professionals is higher, I sense, than it is nearly all of the rest of the time. Essentially, though, the attempt to measure the phenomenon of interest (my blood pressure) changes the phenomenon of interest. The movie "Patch Adams" starring Robin Williams is an example of this dynamic with consequences in the opposite direction. "Patch Adams" is the true story of a physician who has a positive impact on people simply in the way that he intervenes with them. Adams' foil in the movie is his roommate who aces every exam and has the most book knowledge of medicine. He engages in the traditional objective, arms-length relationship with his patients. The roommate (played by Daniel London) has his epiphany when he realizes that although he knows what to prescribe to help a patient, the prescription requires the patient to follow the doctor's instructions, and she won't do so. London's character concedes to Patch Adams's approach while lamenting that 
although he knows everything that needs to be done for this woman, he cannot get her to eat.

I recently experienced this dynamic in a more (economically) painful way. While purchasing a home, I used an internet service which shopped my potential mortgage among a number of companies. I also engaged in my usual financial activity that has allowed for a consistently high credit score. As it turns out, my car died and I needed to purchase a new car the day after I bought the house. The home mortgage came with a rebate if I also applied for and used a credit card. I applied for the credit card, but was denied. The reason: too many recent credit checks about me. American credit bureau scores are FICO (Fair Isaacs and Company) scores. One element of the score is the number of credit checks in a certain period of time. Consequently, simply checking someone's credit can lower their credit rating. The same phenomenon is true of the CPI discussed above. Some elements in the market basket of goods and services are themselves dependent on the CPI level. So increases in the CPI boosts the cost of those items which increases $\mathrm{CPI}$ and the index ratchets inaccurately higher and

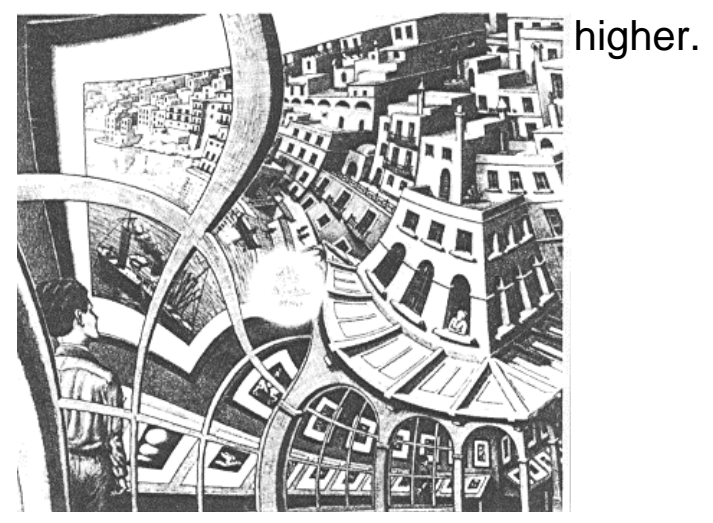


This dynamic is nicely depicted in the Escher drawing in Figure 2. The man is viewing a painting that is revealed to include himself viewing a painting. Presumably, if he as the viewer were to move his hand, he would be changing the painting. The process of inquiry changes the phenomenon of interest.

\section{A Complexity Science Approach to Scholarship with Perspectival Observation}

Complexity theory has opened up a number of new approaches to scholarship for researchers. Two methods will be briefly discussed here.

- $\quad$ discovering patterns in "footprint" data

- looking for and expecting mutually causal phenomena, employing an interaction model rather than one of cause and effect

\section{Footprints}


Ken Wilber has proposed a two-by-two matrix with axes of interior-exterior and individual-collective. It provokes a very comprehensive approach to research that matches the method (and validity assertions) to the type of information sought. For purposes of this section, I will focus on Wilber's upper left quadrant, the interior of the individual. Wilber (2000) claims, "the only way you can know my interior, my depth, is by asking me, by talking to me... And when I report on my inner status, I might be telling you the truth, but I might be lying. You have no other way to get at my interior except in talk and dialogue and interpretation, and I might fundamentally distort, or conceal, or mislead - in short, I might lie" (99).

Complexity theory has suggested that the focus in research should now be on pattern (Bailey, 1996). Wolfram (2002) has written a tome that demonstrates the usefulness of pattern identification as a research method for a variety of phenomena that cannot be understood by other methods. I am suggesting that there is an intriguing opportunity at the intersection of Wilber's interiors and complexity theory's patterns. In Wilber's quote above, he allows for the spoken word to be the research data in the upper left quadrant. It is unclear, though, at what point an inquiry becomes one of an exterior nature. When does "l" data become "it" data? The "l" language is about depth and meaning. I assert that individuals' interiors can be accessed as well through other methods as they can by "talking" and that those methods pose less of a threat of misrepresentation. Both methods described below use interpretation and claim to provide understanding about meaning and depth. As equally problematic as misrepresentation, which Wilber focuses 
on, is the issue of retrospective sense making, in which there is no intended misrepresentation, but simply that human reports do not reflect the relatively spontaneous actions and manifestations of unconscious energy that characterize activity.

Two methods which reflect the interior as good as, or better than, talking, are McClelland's work with thematic apperception tests (TAT) and Jaques' work with coding for human capability. Speech is only one way in which humans reveal their interiors. They also write, draw, communicate non-verbally, and so forth. In fact, it is harder to "lie" through body language than it is through speech. The best poker plays are experts at identifying the "tells" which less capable players exude. The communication sent by the "tell" is more accurate than the betting words, which may be a bluff. In fact, both McClelland and Jaques have tested to see if respondents can "fake" their behaviors to produce a higher reading than would otherwise be accurate, and found that people cannot. An analogy would be to a cognitive test. One cannot outguess the test by performing better than she innately would. She can, however, perform worse than her capability. So, McClelland and Jaques (and other methods focused on patterns) seem to have developed methodologies which surface the depth and address the meaning of the "I" language, with fewer validity threats because they take advantage of the fact that speech is not the only way people reveal their interiors. 
McClelland's $(1953,1961)$ primary focus has been on researching the achievement desires of individuals. Typically he has used TATs in which individuals are shown pictures that are open to wide interpretation, and asked to describe what they see and what the person in the picture is thinking. McClelland and his colleagues then developed a valid and reliable coding method for determining the types of stories respondents would tell that would indicate whether the respondents would likely be high achievers. Of even greater interest is the work in which valid coding has been developed on data sets that do not have to be derived for the research. Studies have correlated doodling and achievement; also, vase designs from archeological findings. If an individual is creating a vase, producing a scholarly article, or arguing a case, without being studied, he has little or no incentive to be anything other than genuine in his behavior.

In his book Human Capability, Elliott Jaques suggests a valid, unobtrusive method for determining an individual's complexity of mental process. Jaques and Cason (1994) discovered that individuals use their highest level of mental process whenever they are speaking passionately about a topic. Their method involves having respondents make the case for an issue. They then employ a coding process on the transcript of the argument. Like McClelland, Jaques has been able to generalize this method to other arenas such as developing a valid way of determining the complexity of mental process of an artist. In my own work, I have developed a coding process for surfacing the 
worldview assumptions of academic and practitioner authors of articles in journals such as Administrative Quarterly and Harvard Business Review (Dent \& Powley, 1999).

\section{Expecting Mutually Causal Phenomena: The Interactional Model}

Complexity theory is being applied to a number of social science questions which contain mutually causal phenomena, those in which variables of interest "evolve and change together in such a way (with feedback and feedforward) as to make the distinction between cause and effect meaningless" (Guba, 1985, 88). If variables cannot be discretely identified as "independent" and "dependent," traditional models of causality become inappropriate, and worse, misleading.

An alternative is for complexity theory researchers to use the "interactional model," shown in Figure 3, to depict the interrelationship among variables (Dent, 2003). This model has interaction as the unit of analysis. Rather than the simplistic formulation of $X$ causes $Y$, it includes $X$ (the cause), $Y$ (the effect), $A$ (the perpetrator of the cause), and $B$ (in the social sciences, the manifestor(s) of the effect), as well as $E$ (the embeddedness or context of all this) and T (interaction over time).

Figure 3. The Interactional Model (adopted from Dent, 2003, 304) 
Organizationally-sanctioned ability of leader to punish resistors?

- Organizational crisis at hand?

- Norms for generally following leaders (conform ity)?

- Norms for personal responsibility?

- O ther workers also asked to work overtime?

- Request was made in a respectful m anner?

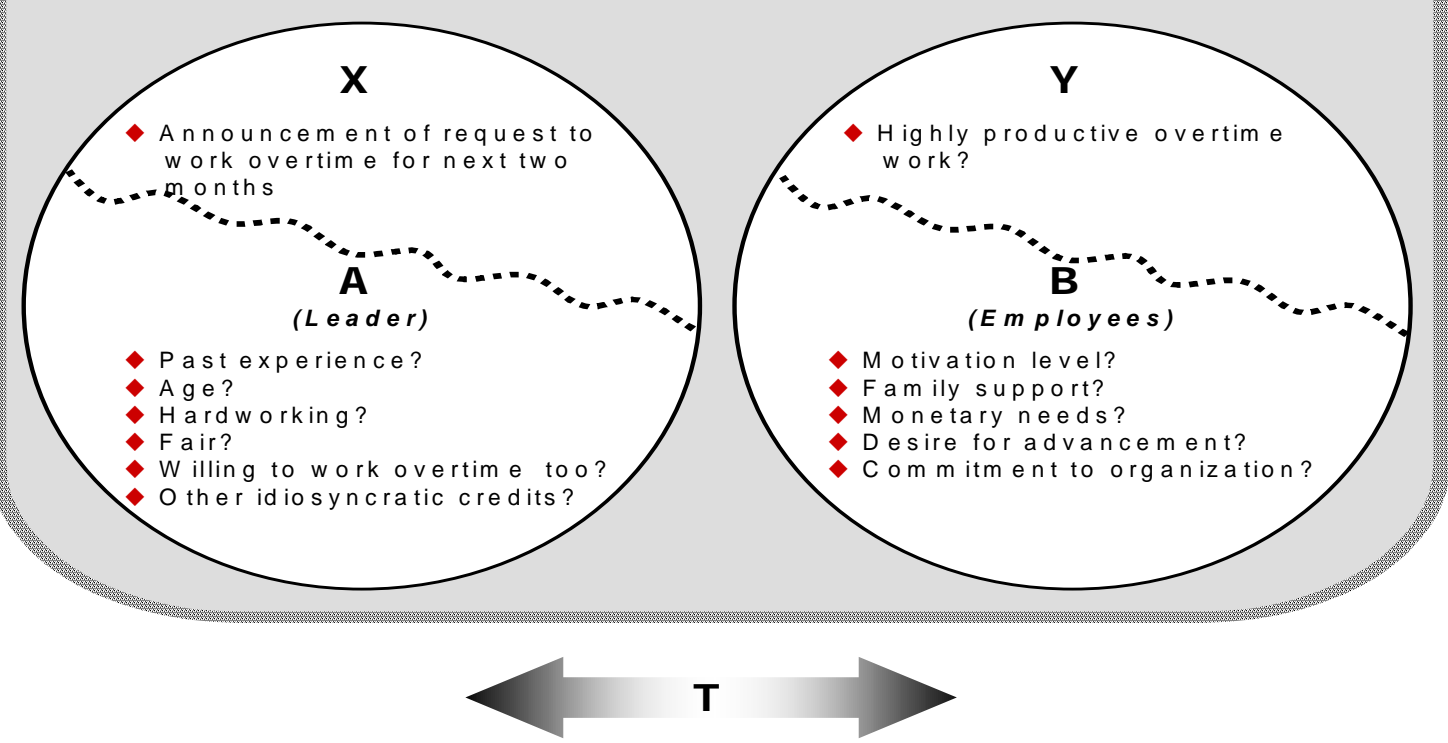

- Established pattern of such requests?

- Early or late in work group's form ation?

- Past performance of group (note)? 

The example in Figure 3 is of a manager $(A)$ announcing a request to work overtime $(X)$, with the expectation that the employees $(B)$, will be more productive $(Y)$. In the classic experimental design, $\mathrm{X}$ and $\mathrm{Y}$ are carefully specified. Little or no attention is paid to $\mathrm{A}$, $B, E$, and $T$. When $A$ is specified, it is usually in terms of demographic information such as age and gender. What is likely more significant is information about "interiors" (Wilber, 2000). Typically, time factors, such as those of Figure 3 are never specified did the request come early or late in the work group's formation, has there been an established pattern of such requests, and so forth.

Since the traditional model of causality has been dominant for hundreds of years, the beginning of attempts at alternatives, such as the interactional model are necessarily crude and cumbersome. Complexity theory either needs to develop more elegant models of interrelationship, or be more rigorous in the specification of additional variables so that the coevolution and emergence of social phenomena can be better understood.

\section{A Complexity Science Approach to Practice with Perspectival Observation}

Complexity theory has also opened up a number of new approaches to more effective performance for organizational practitioners. Two methods will be briefly discussed here. 
- Pursue personal development

- Develop an understanding and appreciation for paradox

\section{$\underline{\text { Pursue Personal Development }}$}

People in Western society are so steeped in objective observation that perspectival observation feels foreign and wrong. However, although research in adult development is still in its infancy, it seems clear that the ability to take multiple perspectives is consistent with higher levels of adult development. In Rajaram Veliyath's chapter, "Dealing with Complexity in Organizational Control Processes: Drawing Lessons from the Human Brain" he goes into greater detail about positive attributes of the brain such as the ability to take multiple perspectives and plasticity.

Kohlberg and Hersh (2001) have found that one of the most dramatic steps in development is between stage 4 and stage 5 . Although as few as nine percent of the American population may achieve this step, it results in a radical widening of perspective. Once someone has achieved this broader frame of reference, she cannot "lose" it. The world has been permanently changed. Consequently, if someone can hasten his or her own development, she is likely to increase personal effectiveness.

Research in adult development has not reached the point of offering definitive guidance about how individuals can trigger their own advancement. It seems clear that 
movement occurs once someone's worldview has been shattered or comes up lacking in a life challenge. However, "society and its institutions provides little incentive for people" to go beyond the Conventional (stages 3 and 4) level of development (Thompson, 2000). I have employed some techniques in consulting which have resulted in participants reaching the "ah ha" experience and possibly increasing their perspective.

I call the primary method I use the "O.J. activity," after O. J. Simpson. I was too busy with other matters to pay attention to the trial of football and movie star O. J. Simpson who was alleged to have murdered his wife. Whether or not he was guilty was a major topic of discussion in 1995-97 as criminal and civil trials were held. I had friends and colleagues whom I admired and thought were brilliant who believed Simpson was innocent. I also had friends and colleagues whom I admired and thought were brilliant who believed Simpson was guilty. Consequently, I became interested in how this difference could be explained. In asking people why they held their belief, I discovered their conclusions were based on quite different assumptions such as the trustworthiness of police, the fairness of the judicial system, whether wealthy people can "buy" their way out of trouble, whether a man could murder the mother of his children, the rigor and interpretation of DNA and other lab tests, and so forth. 
In organizations, I divide a group of people into those who believe he is innocent and those who believe he is guilty. The "innocent" group then must identify what assumptions a person must hold in order for them to rationally and reasonably believe Simpson to be guilty. The "guilty" group works conversely. I use this activity on whatever topic is timely such as a 30 percent tuition increase in a university setting, whether Bill Clinton should have been impeached, whether George W. Bush was rightfully elected, and so forth. Participants report that this exercise forced them to challenge their own assumptions, and to be more facile in understanding a variety of perspectives.

\section{Develop an Understanding and Appreciation for Paradox}

An important partner of objective observation is the universal applicability of logic. Complexity theory work, however, has suggested that paradox may provide greater explanation than logic in an increasing number of situations. Paradoxes should not be seen as implausible. Rather, they "create a tension from which creative solutions emerge" (Regine \& Lewin, 2000, 19). Some see the concept of paradox as so important that they now define leadership as essentially the management of paradoxes (Lewin \& Regine, 2000; Farson, 1996). Peck (1987) asserts that "if a concept is paradoxical, that itself should suggest that it smacks of integrity, that it gives off the ring of truth. Conversely, if a concept is not in the least paradoxical, you should be 
suspicious of it and suspect that it has failed to integrate some aspect of the whole" (238).

Handy (1994) has identified nine principal paradoxes he feels are critical for anyone wanting to understand societies or organizations. These range from the Paradox of Intelligence to the Paradox of the Individual. Farson (1996) identifies as most significant an understanding of the paradoxes of human relations, communication, the politics of management, organizational predicaments, change, and leadership. In the paradox of human relations, for example, research suggests that once a manager finds a technique that works, he must abandon it in order to maintain effectiveness.

Stewart and Cohen (1997) offer the novel Empire Star by science fiction writer Samuel R. Delany as an example of the importance of thinking "multiplexually." In this book, the multiplex mind is one that can simultaneously accept multiple sides of a paradox. "It sees not just one interpretation of reality, but many, yet it sees them as a seamless whole. Such a mind is untroubled by mere inconsistency; it is comfortable with a mutable, adaptive, loosely coherent flux" (289).

\section{Effectiveness in a Perspectival World}

Our conclusion is the same as Delany's - the universe is better understood through the multiple lenses of paradox and perspective. Facility with these lenses will greatly 
increase the effectiveness of individuals in- and outside of work. The science of inquiry needs to develop in different directions. Mihnea Moldoveanu, in the chapter "An Intersubjective Measure of Complexity Grounds: A New Approach to the Study of Organizational Complexity" describes a promising avenue of exploration. An ideal measure is a predictively competent, intersubjectively agreeable algorithmic representation (or computational simulation) of the phenomenon. This measure captures both subjective and objective concerns about the definition of a complexity measure.

Jerry Harvey has described the work of the National Training Laboratory (NTL) in the late 1950 s and early 1960 s as the "Manhattan Project" of group dynamics (Dent, 2002). Conditions are ripe for the emergence of an effort that would be the equivalent of the Manhattan Project in the areas of perspectival observation, emergence, coherence, paradox, and interrelatedness.

\section{References}

Bailey, J. (1996). After thought. New York: BasicBooks [sic]

Cha, A. E. (2001, February 4). Counting web traffic; Which internet sites have the most visitors? It depends on whom you ask, The Washington Post, $\mathrm{H} 01$.

Dent, E. B. (1999). "Complexity science: A worldview shift," Emergence: A Journal of Complexity Issues in Organizations and Management. 1 (4), 5-19.

Dent, E. B. (2002) "The messy history of OB\&D: How three strands came to be seen as one rope," Management Decision, 40(3), 266-280. 
Dent, E. B. (2003). The interactional model: An alternative to the direct cause and effect construct for mutually causal organizational phenomena, Foundations of Science, 8(3), 295-314.

Dent, E. B. \& Powley, E. (1999). "Administrative Sciences Quarterly: Canary of worldview shift?" in Synergy matters: Working with systems in the $21^{\text {st }}$ century, Castell, et al. New York: Kluwer Academic/Plenum Publishers.

Farson, R. (1996). Management of the absurd: Paradoxes in leadership. New York: Simon and Schuster.

Golembiewski, R. \& Munzenrider, R. (1976). Measuring change by OD designs, Journal of Applied Behavioral Science. 12 (April-June), 133-157.

Guba, E. G. (1985). "The context of emergent paradigm research." Organizational theory and inquiry. Lincoln, Y. S. (ed.) Beverly Hills: Sage Publications.

Haggerty, M. (1996, April 16). The Heights of Pride, The Washington Post, D1.

Handy, C. (1994). The age of paradox. Boston: Harvard Business School Press.

Jaques, E. \& Cason, K. (1994). Human capability: A study of individual potential and its application. Arlington, VA: Cason Hall \& Co.

Kohlberg, L., \& Hersh, R. (2001). Moral development: A review of theory. Theory in Practice, 16(2): 53-.

Lewin, R. and Regine, B. (2000). The soul at work: Listen... respond... let go: Embracing complexity science for business success. New York: Simon and Schuster.

McClelland, D. C. (1961). The achieving society. New York: The Free Press.

McClelland, D. C., et al. (1953) The achievement motive. New York: Irvington Publishers, Inc.

Mitroff, I. I. (1974). The subjective side of science: A philosophical inquiry into the psychology of the Apollo moon scientists. Amsterdam : Elsevier.

Murray, I. (2001, July 15). Good news! More people are reporting crimes, The Washington Post, B03. 
Peck, M. S. (1987). The different drum: Community-making and peace. New York: Touchstone.

Planck, M. (1949). Scientific Autobiography and Other Papers. Trans. by Frank Gaynor. New York: Philosophical Library

Regine, B. \& Lewin, R. (2000). "Leading at the edge: How leaders influence complex systems," Emergence: A Journal of Complexity Issues in Organizations and Management. 2 (2), 5-23.

Sandbagging skewed computer flood model. (1997, April 27). The Washington Post.

Schwartz, P. \& Ogilvy, J. (1979). The emergent paradigm: Changing patterns of thought and belief. Menlo Park, CA: SRI International.

Stewart, I., \& Cohen, J. (1997). Figments of reality : the evolution of the curious mind. Cambridge: Cambridge University Press.

Thompson, M. C. (2000). The congruent life: Following the inward path to fulfilling work and inspired leadership. San Francisco: Jossey-Bass.

Wilber, K. (2000). A brief history of everything. $2^{\text {nd }}$ edition. Boston: Shambhala.

Will, G. (1996, September 30). Inflation inflated, Newsweek, 92.

Wolfram, S. (2002). A new kind of science. Champaign, IL : Wolfram Media 